\title{
Sağlıklı Popülasyonda Pnömotonometre ile Göz İçi Basıncı Ölçümü ve Topikal Anestezi Yardımlı Goldmann Aplanasyon Tonometresi Sonrası Değişimi
}

\author{
Kemal Özülken ${ }^{1}$, Çağrı İlhan ${ }^{2} *$ \\ ${ }^{1}$ TOBB Üniversitesi Hastanesi Göz Hastalıkları Anabilim Dalı Ankara, Türkiye. \\ Hatay Devlet Hastanesi Göz Hastalıkları Anabilim Hatay, Türkiye. \\ email:kemalozulken@hotmail.com, cagriilhan@yahoo.com \\ Orcid: 0000-0003-2604-2981 \\ Orcid: 0000-0001-9122-2466 \\ *Sorumlu Yazar / Corresponding Author: Sorumlu Yazar:Çağrı İlhan \\ Gönderim Tarihi / Received: 11.03.2019 \\ Kabul Tarihi / Accepted: 08.08.2019 \\ DOI: $10.34087 /$ cbusbed.538422
}

\begin{abstract}
Amaç: Sağlıklı popülasyonda, pnömotonometre ve topikal anestezi yardımlı Goldmann aplanasyon tonometresi (GAT) ile ölçülen göz içi basıncı (GIB) değerlerinin ve GAT öncesi ve sonrası pnömotonometre ile elde edilen GİB değerleri ile karşıslaştırılması.

Gereç ve Yöntemler: Refraksiyon muayenesi için başvuran, herhangi bir göz hastalığı olmayan, Kafkas urkından, 103 sağlıklı olgunun să̆ gözüne önce pnömotonometre ile sonra da topikal anestezi damlatılarak GAT ile GïB ölçüldü. GAT ile GIB ölçümünden $10 \mathrm{dk}$ sonra topikal anestezi etkisi altında pnömotonometre ile GIB ölçümü tekrarlandı. Pnömotonometre ve GAT ölçümleri karşılaştırılarak iki farklı yöntemin sonuçları arasında fark olup olmadığı değerlendirildi. Ayrıca GAT öncesi ve sonrası pnömotonometre ile elde edilen GỉB değerleri karşılaştırılarak topikal anestezinin pnömotonometre ile elde edilen GiB değeri üzerine etkisi olup olmadığ 1 araştırıldı.
\end{abstract}

Bulgular: 55'i erkek, 48'i kadın ( $\mathrm{p}=0,762) 103$ olgunun ortalama yaş1 48,32 \pm 9,62 y1l $(18-65)$ ve 45,30 $\pm 8,78$ y1l $(18-65)$ idi $(p=0,664)$. Pnömotonometre ile ölçülen ortalama Gİ 20,50 $\pm 3,31 \mathrm{mmHg}(12-26)$ iken GAT ile ölçülen ortalama GIB 19,93 $\pm 3,13 \mathrm{mmHg}(12-28)$ idi (p <0,001). GAT sonrası tekrarlanan pnömotonometre ile ölçülen ortalama GIB 19,05 $\pm 3,13 \mathrm{mmHg}(12-26)$ idi ve bu değer GAT öncesi pnömotonometre ile ölçülen GİB değerinden düşüktü $(\mathrm{p}<0,001)$.

Sonuç: Sağlıklı popülasyonda pnömotonometre ile elde edilen GİB değeri topikal anestezi yardımlı GAT ile elde edilen değerden yüksektir ve bu değer GAT ile GİB ölçümünden $10 \mathrm{dk}$ sonra düşmektedir. Hem GAT ile GIBB ölçümü öncesi hem de sonrası pnömotonometre ile elde edilen GïB değerleri GAT ile elde edilen değerlerle koreledir.

Anahtar Kelimeler: Göz İçi Basınc1, Pnömotonometre, Goldmann Aplanasyon Tonometresi, Glokom, Topikal Anestezi.

Abstract
Objectives: In healthy population, comparison of IOP values measured with pneumotonometer and
topical anesthesia assisted Goldmann applanation tonometer (GAT), and IOP values measured with
pneumotonometer pre- and post-GAT.
Materials and Methods: Right eyes of 103 healthy Caucasian subjects with no eye disease who were admitted for
refractive examination were included in the study. IOP was measured first by pneumotonometer and then with GAT
under topical anesthesia. After that IOP measurement was repeated with pneumatonometer under the effect of
topical anesthesia 10 minutes after IOP measurement with GAT. Pneumotonometer and GAT measurements were
compared to determine whether there were any differences between the results of two different methods. In addition,
pre-GAT and post-GAT IOP values measured with pneumotonometer were compared and it was investigated
whether topical anesthesia had an effect on the IOP measurement with pneumotonometer.


Results: The mean age of 103 cases with 55 males and 48 females $(\mathrm{p}=0.762)$ was $48.32 \pm 9.62$ years $(18-65)$ and $45.30 \pm 8.78$ years $(18-65)(\mathrm{p}=0.664)$. The mean IOP values measured with pneumotonometer and GAT were $20,50 \pm 3,31 \mathrm{mmHg}(12-26) 19,93 \pm 3,13 \mathrm{mmHg}(12-28)(\mathrm{p}<0,001)$. The mean IOP measured with pneumotonometer after GAT measurement was $19.05 \pm 3.13 \mathrm{mmHg}(12-26)$ and this value was lower than the IOP measured by pneumotonometer before GAT $(\mathrm{p}<0.001)$.

Conclusion: In healthy population, IOP measured by pneumotonometer is higher than the value obtained by topical anesthesia assisted GAT and this value decreases $10 \mathrm{~min}$ after GAT. Both of pre-GAT and post-GAT IOP values measured with pneumotonometer are correlated with IOP values measured with GAT.

Key Words:Intraocular Pressure, Pneumotonometer, Goldmann Applanation Tonometer, Glaucoma, Topical Anesthesia.

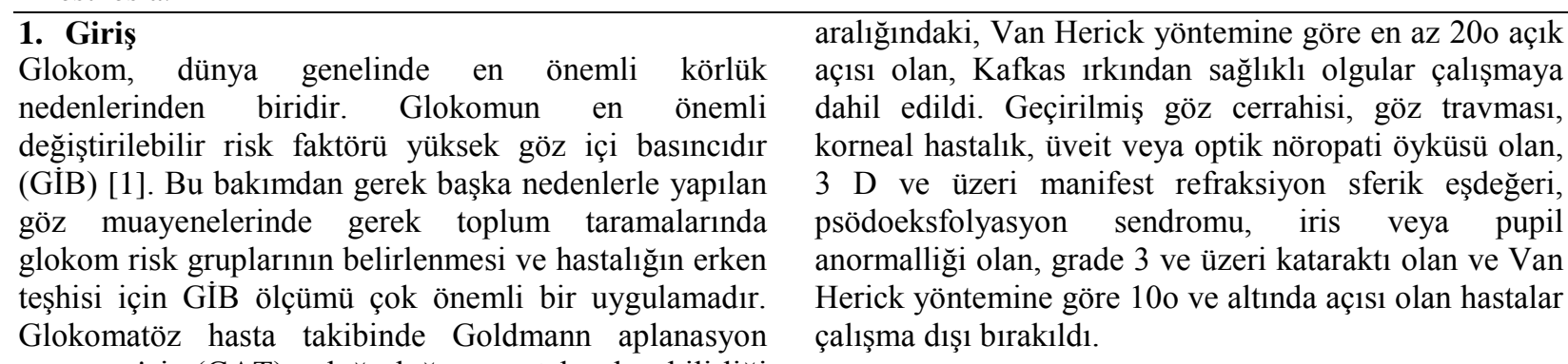
tonometrisi (GAT), doğruluğu ve tekrarlanabilirliği bakımından altın standart yöntem olarak kabul edilmektedir [2]. Topikal anestezi sonrası korneal yüzey üzerine uygulanan kuvvet ile belirli bir korneal alanın düzleştirilmesi ilkesine dayanan bu yöntem, uygulanmasının tecrübe ve hasta uyumu gerektirmesi bakımından tarama için pratik değildir. Uygulanan topikal anestezinin gerek oküler yüzey gerek ön segment üzerine bilinen ve halen araştırılan birçok etkileri vardır [3,4]. Klinik çalışmalarda farklı GİB ölçüm yöntemleri, daha konforlu bir muayene ve güvenilir bir sonuç sağlamasının araştırılması bakımından GAT ile karşılaştırılmaktadır. Pnömotonometre ile topikal anestezi veya korneal temas olmadan, hava akımı yoluyla korneal düzleşme ve indentasyon yaparak GİB ölçümü sağlanmaktadır. Pratik bir yöntem olması ve korneal yüzey özelliklerinden daha az etkilenmesi bakımından poliklinik rutininde sıklıkla kullanılan bir yöntemdir [5].

Kafkas ırkından sağlıklı popülasyonda gerçekleştirilen bu çalışmada birincil olarak, pnömotonometre ve GAT ile elde edilen GİB değerlerinin karşılaştırılarak iki yöntem arasındaki farklılığın; ikincil olarak ise GAT öncesi ve topikal anestezi etkisi altında GAT sonrası pnömotonometre ile elde edilen GİB değerlerinin karşılaştırılarak topikal anestezi damlasının GİB değeri üzerine etkisi olup olmadığının araştırılması amaçlanmaktadır.

\section{Gereç ve Yöntem}

Etik kurul onayı alınmasının ardından (TOBB ETÜ Tıp Fakültesi Klinik Araştırmalar Etik Kurulu, Karar No:028, Tarih:17.04.2019), TOBB ETÜ Hastanesi Göz Hastalıkları Polikliniğinde gerçekleştirilen geriye dönük, randomize olmayan, olgu kontrol çalışmasında Helsinki Deklarasyonu'na sadık kalındı. Polikliniğe refraksiyon muayenesi için başvuran, herhangi bir bilinen göz hastalığ 1 olmayan, en iyi düzeltilmiş görme keskinliği değeri en az 0.00 logMAR olan, 18 - 65 yaş

Çalışmaya dahil edilen tüm olgulara muayene öncesi pnömotonometre (HNT-7000, Huvitz, Güney Kore) ile GIB ve ultrasonik pakimetre (Pachymeter P-2200; Paradigm Medical Industries, Salt Lake City, UT, ABD) ile merkezi kornea kalınlığı ölçümleri yapıldı. Snellen eşeli ile en iyi düzeltilmiş görme keskinliği, ön segment, Van Herick yöntemiyle ön kamara açısı ve fundus muayenesini takiben topikal \% 0,5 proparakain (Alcaine, Alcon, Fort Worth, TX, ABD) ile anestezi ve \% 0,25 flöresein ile korneal boyanma sonrası GAT (Haag-Streit AG, Koeniz, İsviçre) ile GİB ölçüldü. GAT ile yapılan GİB ölçümü sonrası olgulardan $10 \mathrm{dk}$ süresince oturarak istirahat etmeleri istendi ve pnömotonometre ile GİB ölçümü tekrarland1. Gerek deneyimli teknisyen tarafından gerçekleştirilen pnömotonometre ölçümleri gerek tek hekim (KÖ) tarafından gerçekleştirilen GAT ölçümleri ardışık 3 ölçümün aritmetik ortalaması alınarak kayıt edildi. Tüm muayeneler sabah saat 09.00 ile öğlen 12.00 saatleri arasında yapıldı ve sonuçlar geriye dönük olarak hasta kayıt kartları üzerinden değerlendirildi.

İstatistiksel araştırmaya tüm hastaların sağ gözlerinin verileri dahil edildi. İstatistiksel araştırma Statistical Package for Social Sciences (SPSS) 24,0 versiyon (IBM, Chicago, IL, ABD) ile gerçekleştirildi. Tanımlayıcı veriler ortalama $\square$ standart sapma (en düşük - en yüksek değerler) şeklinde verildi. Kategorik veriler ki-kare testi ile analiz edildi. KolmogorovSmirnov testi ile verilerin normal dağılıma uygunluğu değerlendirildi. Veriler normal dağılıma uymadığı için parametrik olmayan Wilcoxon testi kullanıldı. Pearson korelasyon analizi ile farklı yöntemlerle elde edilen sonuçların korelasyonu araştırıldı. Tüm testler için 0,05’ten küçük p değerleri anlamlı kabul edildi.

\section{Bulgular}

Çalışmaya dahil edilen Kafkas ırkından 103 olgunun 55'i erkek, 48'i kadındı ( $\mathrm{p}=0,762)$. Erkek olgularda 
ortalama yaş 48,32 $\square 9,62$ yıl $(18-65)$ iken kadın olgularda 45,30 - 8,78 yıl $(18-65)$ idi $(\mathrm{p}=0,664)$.

Çalışma grubunda ortalama merkezi kornea kalınlığ 554,42 - 33,25 -m (469 - 638) idi. Pnömotonometre ile ölçülen ortalama GİB değeri 20,50 $\square 3,31$ mmHg (1226) idi. GAT ile ölçülen ortalama GİB değeri ise 19,93 $\square$ 3,13 mmHg (12 - 28) idi. Pnömotonometre ile elde edilen ortalama GIBB değeri GAT ile elde edilen değerden yüksekti (p <0.001). GAT sonrası pnömotonometre ile ölçülen ortalama GİB değeri ise $19,05 \square 3,13 \mathrm{mmHg}(12$ - 26) idi. GAT sonrası pnömotonometre ile ölçülen ortalama GİB değeri GAT öncesi ölçülen değerden anlamlı olarak düşüktü ( $p$ $<0,001)$. GAT öncesi ve sonrası pnömotonometre ile ölçülen GİB değerleri Tablo 1'de özetlendi ve Şekil 1 'de gösterildi. Hem GAT öncesi ( $r=0,90$ ve $p<0,001)$ hem de GAT sonrasi $(\mathrm{r}=0,87$ ve $\mathrm{p}<0,001)$ pnömotonometre ile ölçülen GİB değerleri, GAT ile ölçülen GİB değerleriyle anlamlı şekilde korele idi.

Tablo 1. Farklı yöntemlerle elde edilen GİB değerleri.

\begin{tabular}{|c|c|c|c|}
\hline & GAT & $\begin{array}{c}\text { GAT öncesi } \\
\text { pnömotonometre }\end{array}$ & $\begin{array}{c}\text { GAT sonras1 } \\
\text { pnömotonometre }\end{array}$ \\
\hline $\begin{array}{l}\text { GïB } \\
(\mathrm{mmHg})\end{array}$ & $19.93 \pm .13$ & 20.5 & 19. \\
\hline \multicolumn{4}{|c|}{$\begin{array}{l}\text { GİB: Göz içi basıncı. GAT: Goldmann aplanasyon } \\
\text { tonometresi. } \\
\text { p <0.001 GAT öncesi pnömotonometre ve GAT sonrası } \\
\text { pnömotonometre karş1laştırması. } \\
\text { r }=0.90 \text { ve p <0.001 GAT öncesi pnömotonometre ile } \\
\text { GAT korelasyonu. } \\
\text { r =0.87 ve p <0.001 GAT sonrası pnömotonometre ile } \\
\text { GAT korelasyonu. }\end{array}$} \\
\hline
\end{tabular}

Şekil 1. Goldmann aplanasyon tonometresi öncesi ve sonrası pnömotonometre ile elde edilen göz içi basıncı değerleri.

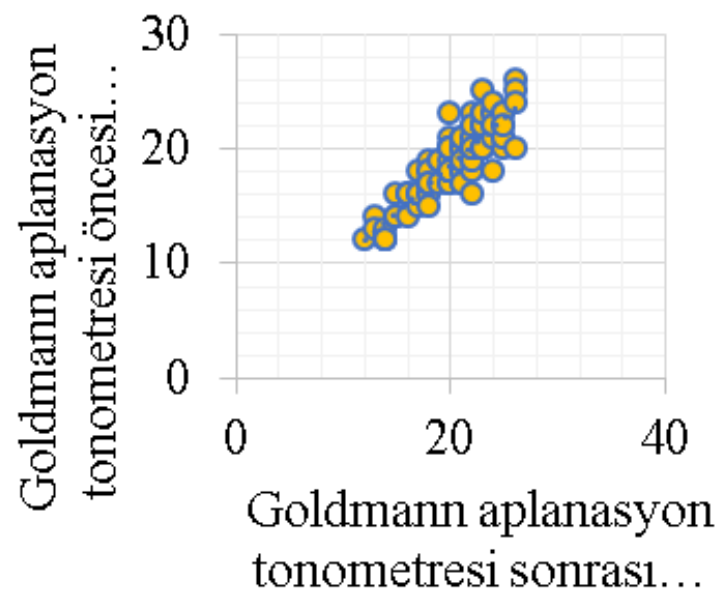

\section{Tartışma}

Literatürde sağlıklı popülasyonda farklı pnömotonometre cihazlarıyla yapılmış çalışmalarda, elde edilen GIBB değerlerinin GAT ile elde edilenlerden daha yüksek olduğunu bildiren yayınlar vardır [6,7].
Bununla birlikte, birçok çalışma GAT ile ölçülen GİB değerinin $\square 3 \mathrm{mmHg}$ içindeki, farklı yöntemle ölçülmüş GIB değerinin kabul edilebilir olduğunu bildirmektedir $\square 8, \quad 9 \square$. Çalışmanın sonucu bu bakımdan değerlendirildiğinde pnömotonometre ile ölçülen GİB değerinin, GAT ile ölçülen GİB değerinden yüksek olmasına rağmen, bu değere oldukça yakın olduğu ve $\square$ $3 \mathrm{mmHg}$ aralığında bulunduğu görülmektedir. Ülkemizden Marangoz ve ark. $\square 10 \square$ da sağlıklı çalışma grubunda pnömotonometre ile elde ettikleri GIB değerlerinin GAT ile elde edilen değerlere yakın olduğunu bildirmektedir.

Çalışmanın test ettiği diğer bir nokta GAT ile GIBB ölçümü protokolünün pnömotonometre ile elde edilen GİB değeri üzerine olan etkisidir. GAT ile GİB ölçümünde topikal proparakain anestezisi ülkemizde en sık kullanılan yöntemdir ve literatürde topikal proparakain uygulamasının GİB üzerine etkileri ile ilgili çok sayıda çelişkili yayın vardır. Ko ve ark. [11], Nam ve ark. [12] ve Herse ve Siu [13] topikal proparakain uygulaması sonrası korneal kalınlık ve GİB değerlerinde geçici artış olduğunu bildirmişlerdir. Buna karşılık Almubrad ve Ogbuehi [14] topikal proparakain sonrası GIBB değerinde azalma olduğunu rapor etmiştir. Ogbuehi [15] topikal oksibuprokain ve tetrakain uygulamalarının GİB değerinde istatistiksel anlamlı azalmaya neden olurken korneanın biyomekanik özelliklerinde değişikliğe neden olmadığını bildirmişlerdir. Kim ve ark. [16] köpek gözlerinde topikal proparakain sonrası GIBB değerinde herhangi bir değişiklik olmadığını bildirmelerine rağmen Sarchahi ve Eskandari [17] kendi çalışmalarında, topikal proparakainden $10 \mathrm{dk}$ sonra GİB değerinde anlamlı azalma olduğunu göstermişlerdir.

Kafkas ırkından sağlıklı popülasyonda yapılan bu çalışmanın sonuçlarına göre topikal proparakain anestezisi uygulanarak gerçekleştirilen GAT ile GIBB ölçümünden $\quad 10 \quad \mathrm{dk} \quad$ sonra gerçekleştirilen pnömotonometre ile GİB ölçümü değerinde anlamlı azalma olmaktadır. Bu sonuç birçok farklı açıdan ele alınabilir: Topikal proparakain anestezisi sonrası korneal relaksasyonda artış ve korneal kalınlıkta değişiklik olmaktadır [3,4]. Her ne kadar episkleral venöz basınç değişmese de silyer kaslardaki kasılma ve ardıl mekanizmalarla aköz drenajının teorik olarak $\operatorname{arttığ1~düşünülmektedir~[18].~Bununla~birlikte~GIBB~}$ ölçümünden önce göze topikal anestezik uygulanması, gözyaşı filminde fluoresanın seyrelmesine neden olabileceğini ve GİB ölçümünün yanlışlıkla düşük ölçülmesi ile sonuçlanabileceğini gösteren çalışmalar mevcuttur [19]. Ayrıca GAT ve topikal anestezi altında pnömotonometre ile ölçülen GİB değerlerinin düşük çıkmasının bir başka sebebinin, daha önceki pnömotonometre ile alınan ölçümler sırasında endişeli olan hastaların göz sıkma veya valsalva manevrası sonucunda GİB değerlerinin yanlış yüksek çıkmış olabileceğini düşünmekteyiz.

$\mathrm{Bu}$ çalışmanın en güçlü yanı çalışma grubunun birçok bakımdan homojen olmasıdır. Psödoeksfolyasyon ve dar 
açı1ı hastaların çıkarıldığı bu büyük çalışma grubunda, gerek hastaların yüksek astigmatizmaya veya yoğun katarakta sahip olmaması gerek ölçümlerin günün benzer saatinde sabit bir protokole sadık kalınarak elde edilmiş olması sonuçların güvenilirliğini artıran durumlardır. GAT sonrası merkezi korneal kalınlık ölçümünün tekrarlanmamış olması, sadece 10. dakikada pnömotonometre ile ölçüm alınarak GIBB monitörizasyonu yapılmamış olması ve verilerin geriye dönük incelenmiş olması ise çalışmanın önemli kısıtlılıklarıdır. Ayrıca bu çalışmadaki istatistiksel anlamlı sonuçların klinik önemi de bilinmemektedir.

Sonuç olarak, Kafkas ırkından sağlıklı popülasyonda, pnömotonometre ile elde edilen GİB değeri topikal anestezi yardımlı GAT ile elde edilen değerden yüksektir. GAT öncesi pnömotonometre ile ölçülen GİB değeri, GAT ile GİB ölçümünden $10 \mathrm{dk}$ sonra düşmektedir. Hem GAT ile GİB ölçümü öncesi hem de sonrası pnömotonometre ile elde edilen GIBB değerleri GAT ile elde edilen değerlerle koreledir.

\section{Kaynaklar}

1. Quigley HA, Number of people with glaucoma worldwide. British Journal of Ophthalmolology, 1996, 80, 389-393.

2. Elmallah MK, Asrani SG, New ways to measure intraocular pressure, Current Opinion in Ophthalmolology, 2008, 19, $122-126$.

3. Montero J, Ruiz-Moreno J, Fernandez-Munoz M, RodriguezPalacios M, Effect of topical anesthetics on intraocular pressure and pachymetry, European Journal of Ophthalmolology, 2008,18,748-750.

4. Cunningham AJ, Barry P, Intraocular pressure- physiology and implications for anaesthetic management, Canadian Journal of Anesthesia, 1986,33,195-208.

5. Rosentreter A, Jablonski KS, Mellein AC, Gaki S, Hueber A, Dietlein TS, A new rebound tonometer for home monitoring of intraocular pressure, Graefe's Archives for Clinical and Experimental Ophthalmolology, 2011,249,1713-1719.

6. Brencher HL, Kohl P, Reinke AR, Yolton RL, Clinical comparison of air-puff and Goldmann tonometers, Journal of American Optometry Association, 1991,62,395-402.

7. Lomoriello DS, Lombardo M, Tranchina L, Oddone F, Serrao S, Ducoli P. Repeatability of intra-ocular pressure and centra corneal thickness measurements provided by a non-contact method of tonometry and pachymetry. Graefe's Archieve for Clinical and Experimental Ophthalmology, 2011,249,429434.

8. Carbonaro F, Andrew T, Mackey DA, Spector TD, Hammond CJ, Comparison of three methods of intraocular pressure measurement and their relation to central corneal thickness, Eye, 2010,24,1165-1170.

9. Kim KN, Jeoung JW, Park KH, Yang MK, Kim DM, Comparison of the new rebound tonometer with Goldmann applanation tonometer in a clinical setting, Acta Ophthalmology, 2013,91, 392-396.

10. Marangoz D, Kohen MC, Altunsoy M, Yalvac I, Farkl tonometreler ile yapılan göz içi basıncı ölçümlerinin kornea kalınlığına göre analizi, Turkiye Klinikleri Journal of Ophthalmology, 2017,26,193-197.

11. Ko Y, C-1 Liu, Hsu W, Varying effects of corneal thickness on intraocular pressure measurements with different tonometers, Eye, 2005,19,327-332.

12. Nam SM, Lee HK, Kim EK, Seo KY, Comparison of corneal thickness after the instillation of topical anesthetics: proparacaine versus oxybuprocaine, Cornea, 2006,25,51-54.

13. Herse P, Siu A, Short-term effects of proparacaine on human corneal thickness, Acta Ophthalmology, 1992,70,740-744

14. Almubrad TM, Ogbuehi $\mathrm{KC}$, Clinical investigation of the effect of topical anesthesia on intraocular pressure, Clinical
Ophthalmology, 2007,1,305-309.

15. Ogbuehi KC, Corneal biomechanical parameters and intraocular pressure: the effect of topical anesthesia, Clinical Ophthalmology, 2012, 6,871-878.

16. Kim J, Kim NS, Lee KC, Lee HB, Kim MS, Kim HS, Effect of topical anesthesia on evaluation of corneal sensitivity and intraocular pressure in rats and dogs, Veterinary Ophthalmology, 2013,16,43-46.

17. Sarchahi AA, Eskandari M, Effect of four local anesthetics (tetracaine, proparacaine, lidocaine, and bupivacaine) on intraocular pressure in dogs, International Ophthalmology, 2018, Jun 23. doi: 10.1007/s10792-018-0969-0. [Epub ahead of print]

18. Malihi, M, McLaren JW, Sit AJ, Effect of topical anesthesia on episcleral venous pressure in normal human subjects, Investigative Ophthalmology \& Visual Science, 2015,56,2968-2970

19. Baudouin, C, Gastaud P, Influence of topical anesthesia on tonometric values of intraocular pressure, Ophthalmologica, $1994,208,309-313$

http://edergi.cbu.edu.tr/ojs/index.php/cbusbed isimli yazarın CBU-SBED başlıklı eseri bu Creative Commons Alınt-Gayriticari4.0 Uluslararası Lisansı ile lisanslanmıştır. 